\title{
ANALYSIS APPROACH FOR THREE PHASE TWO-LEVEL VOLTAGE SOURCE INVERTER AND FIVE PHASE TWO-LEVEL VOLTAGE SOURCE INVERTER FOR INDUCTION MOTOR DRIVE
}

\author{
Ankur P. Desai ${ }^{1}$, Rakesh J. Motiyani ${ }^{2}$, Vijay G. Bhuva ${ }^{3}$, Jignesh P.Desai ${ }^{4}$ \\ ${ }^{1}$ Student, Shantilal Shah Engineering College, Bhavnagar, Gujarat, India, ${ }^{2}$ Associate Professor, S.N.Patel Institute of \\ Technology, Bardoli, Gujarat, India, ${ }^{3}$ Assistant Professor, Shantilal Shah Engineering College, Bhavnagar, Gujarat, \\ India, ${ }^{4}$ Student, Nirma University, Ahemdabad, Gujarat, India, ankurdesai.vbt12345@gmail.com, \\ motiyani_me@rediffmail.com,vijay_bhuva@yahoo.com,11meee04@nirmauni.ac.in
}

\begin{abstract}
This paper gives idea of comparison of three phase two-level voltage source inverter (TPTLVSI) and five phase two-level voltage inverter (FPTLVSI) without filter circuit for induction motor drive. The paper demonstrates using mat lab simulations about comparison in term of harmonics analysis for different firing angles and find best angle suitable for output with minimum harmonics for FPTLVSI. This paper suggests simulation of comparison point of view three phase two-level voltage inverter (TPTLVSI) and five phase two-level voltage inverter (FPTLVSI) for induction motor drive.
\end{abstract}

Index Terms: Modeling of Three phase two-level voltage inverter (TPTLVSI) and five phase two-level voltage inverter (FPTLVSI)

\section{INTRODUCTION}

RESEARCH interest in the area of multiphase machines has been steadily increasing over the past decade [1].The newest developments are application-driven (marine electric propulsion, electric vehicles (EVs) and hybrid electric vehicles (HEVs), more electric aircraft, locomotive traction, and high-power applications in general) and the consequence of the advantages offered by multiphase machines, when compared to the threephase equivalents. These are predominantly related to the possibility of reduction of the converter per-phase rating for the given machine power and to significantly improved fault tolerance, since an n-phase machine can continue to operate with a rotating field as long as no more than $(n-3)$ phases are faulted. A further advantage exists if the multiphase machine is designed with concentrated stator windings, since it then becomes possible to enhance the torque production by injection of the low-order stator current harmonics of an appropriate order. five phase induction machine drive.

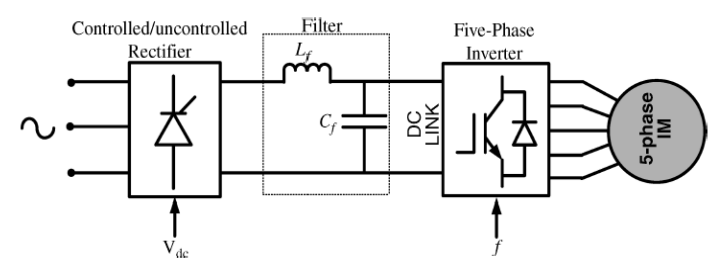

Fig.1 Block diagram of five phase induction motor drive
A simple open-loop five-phase drive structure is elaborated in Error! Reference source not found.. The dc link voltage is adjusted from the controlled rectifier by varying the conduction angles of the thyristors. The frequency of the fundamental output is controlled from the IGBT based voltage source inverter. The subsequent section describes the implantation issues of control of a five-phase voltage source inverter. The motivation behind choosing this structure lies in the fault tolerant nature of a fivephase drive system. It has been advantage of five phase induction motor drive like reduction in phase current, reliable in faulty conditions, reduction in current ripple.

\section{BLOCK DIAGRAM FIVE PHASE TWO LEVEL}

\section{VOLTAGE SOURCE INVERTER MODEL}

As shown in fig.2 each switch in the circuit consists of two power semiconductor devices connected in anti-parallel. One of these is a fully controllable semiconductor, such as a bipolar transistor, MOSFET, or IGBT, while the second is a diode.

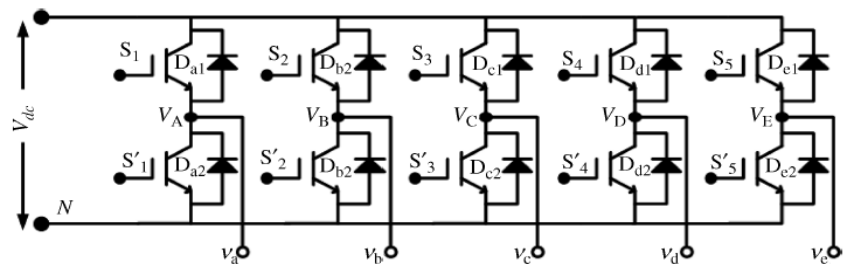

Fig.2 Power Circuit topology of a FPTLVSI 
The upper and lower power switches of the same leg are complimentary in operation, i.e. if the upper switch is ' $\mathrm{ON}$ ' the lower must be 'OFF,' and vice-versa. As shown in fig.3 Dead time is done to avoid shorting the DC supply.

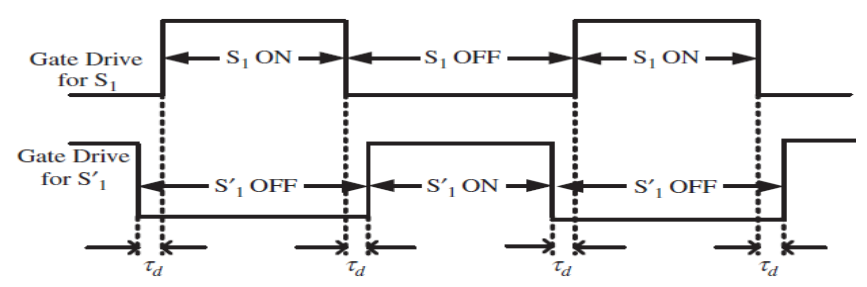

Fig.3 Illustration for dead time

\section{HARMONICS ANALYSIS OF TPTLVSI AND FPTLVSI}

This section presents the comprehensive analysis of simulation results. The performance of two different conduction modes are elaborated in terms of the harmonic content in the phase voltages, line voltages and the distortion in the ac side line current. The Fourier series of the phase-to-neutral voltage for $180^{\circ}$ conduction mode is obtained as;

$$
V(t)=\frac{2}{\pi} V_{d c}\left[\begin{array}{l}
\sin \omega t+\frac{1}{3} \sin 3 \omega t+ \\
\frac{1}{7} \sin 7 \omega t+\frac{1}{9} \sin 9 \omega t+ \\
\frac{1}{11} \sin 11 \omega t+\ldots . .
\end{array}\right]
$$

From above equation (1) it follows that the fundamental component of the output phase-to-neutral voltage has an RMS value equal to

$$
V_{1}=\frac{\sqrt{2}}{\pi} V_{d c}=0.45 V_{d c}
$$

The Fourier series of the phase-to-neutral voltage for $120^{\circ}$ conduction mode is obtained as;

$V(t)=\frac{2 V_{d c}}{\pi} \sum_{n=1,2,3, \ldots}^{\infty}\left[\frac{\cos \left((2 n-1) \frac{\pi}{10}\right) \sin ((2 n-1) \omega t)}{2 n-1}\right]$

From above equation (3) it follows that the fundamental component of the output phase-to-neutral voltage has an RMS value equal to

$$
V_{1}=\frac{\sqrt{2}}{\pi} V_{d c} \cos \left(\frac{\pi}{10}\right)=0.428 V_{d c}
$$

As per the equation of (4) loss in fundamental voltage in $120^{\circ}$ conduction mode is of the order of $4.89 \%$ compared to $180^{\circ}$ conduction mode. This loss will affect the loss of torque in the driven machine and subsequently the load will be affected. However, the drop in the torque is not very significant compared to the benefits obtained due to better harmonic performance.

Performance comparison in terms of harmonic content in output phase voltage, for different conduction modes are presented in fig.10 to 11Error! Reference source not found.. It is clearly seen that the harmonic content reduces significantly with reduction in conduction angle. The harmonic content is largest in 180 degree conduction mode and it is least in 120 degree conduction mode. However, the best utilization of available dc link voltage is possible with conventional ten step mode (180 degree conduction mode). It can thus be concluded that a tradeoff exist between the loss in fundamental and corresponding gain in terms of lower harmonic content in output waveform is obtained by using 120 degree conduction mode.

A comparison of total harmonic distortion in the output phase voltages of five-phase voltage source inverter for different conduction angle is presented. The conduction angles considered are $180^{\circ}, 162^{\circ}, 144^{\circ}, 126^{\circ}$, and $108^{\circ}$. Thus two more conduction states are included when compared to further prove the superiority of control at $120^{\circ}$ conduction mode. It is observed that the lowest THD is obtained for $120^{\circ}$ conduction mode.

\section{MATLAB/SIMULINK MODELING OF TPTLVSI AND FPTLVSI}
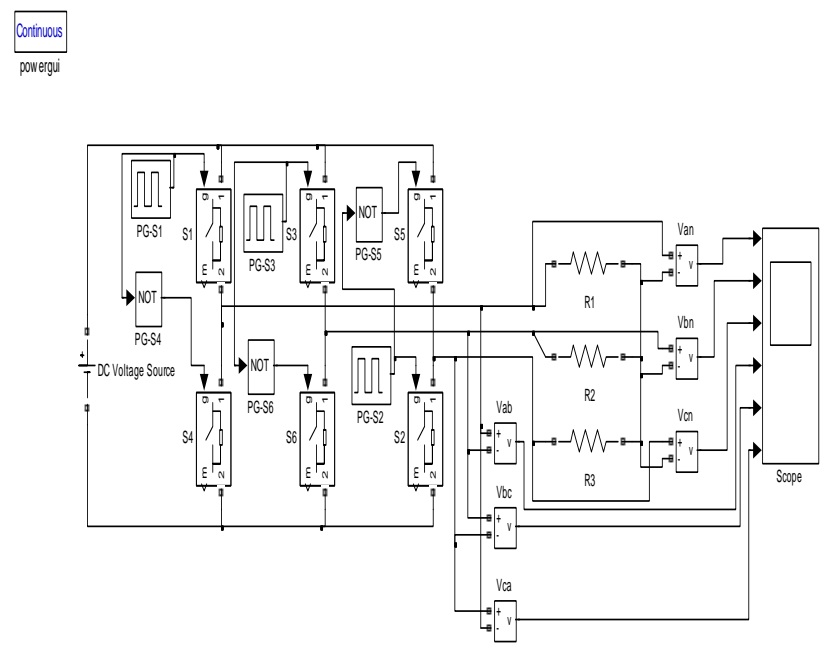

Fig.4 Matlab/simulink of model of TPTLVSI 


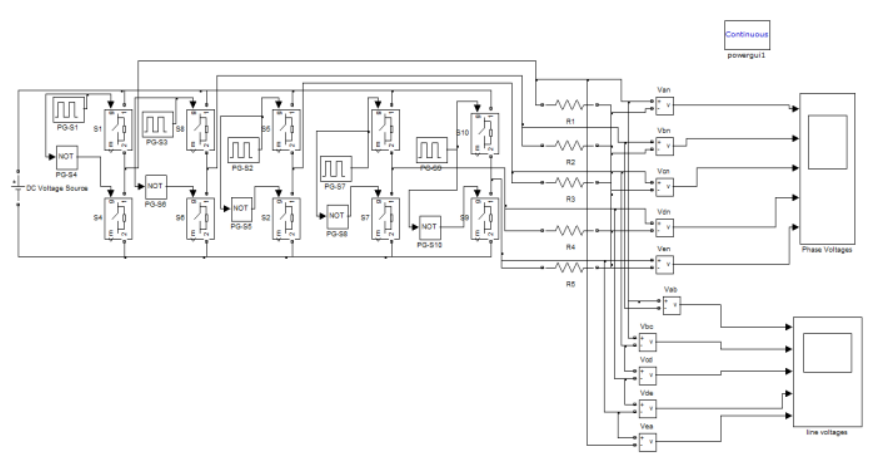

Fig.5 Matlab/simulink of FPTLVSI

Above fig. 4 is mat lab simulation of TPTLVSI with balance resistive load. It can be simulated as different firing angles of power electronics switches. Similarly Fig.5 is also mat lab simulation of FPTLVSI with balance resistive load. It can be simulated and analysis for different firing angles and takes measurement of harmonics behavior.

Following Table1 shows THD Vs different firing angles for FPTLVSI without any filter circuit.

Table: 1 Different firing angles and related THD for harmonic analysis of FPTLVSI

\begin{tabular}{|l|l|}
\hline Firing angles & THD(Total Harmonics Distortion) \\
\hline 108 & 53.63 \\
\hline 110 & 49.96 \\
\hline 115 & 47.3 \\
\hline 118 & 36.99 \\
\hline 120 & 27.03 \\
\hline 125 & 36.28 \\
\hline 126 & 35.68 \\
\hline 130 & 38.51 \\
\hline 144 & 42.98 \\
\hline 180 & 46.68 \\
\hline
\end{tabular}

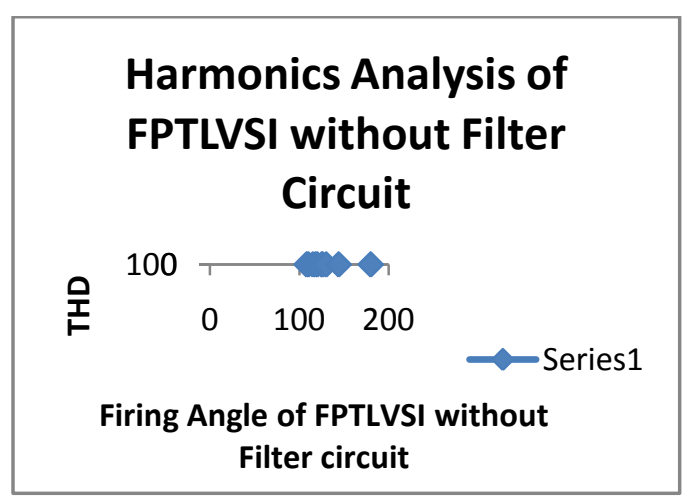

Fig.6 curve of different firing angles and related THD for harmonic analysis of FPTLVSI

\section{RESULTS}

Matlab/simulation results of three phase two-level voltage source inverter and five phase two-level voltage source

Simulation results of for TPTLVSI and FPTLVSI the operating conditions given below are shown in Fig.7 to fig.11. Simulation results show output phase voltages, line voltage currents, gate triggering, load current, harmonics analysis for three phase twolevel inverter and five phase two level voltage inverter.

Operating condition:

Simulation time: $0.02 \mathrm{sec}$

DC Link Voltage Vdc $=200 \mathrm{~V}$ before running simulation given in command prompt.

Freq $=50 \mathrm{~Hz}$ running simulation given in command prompt.
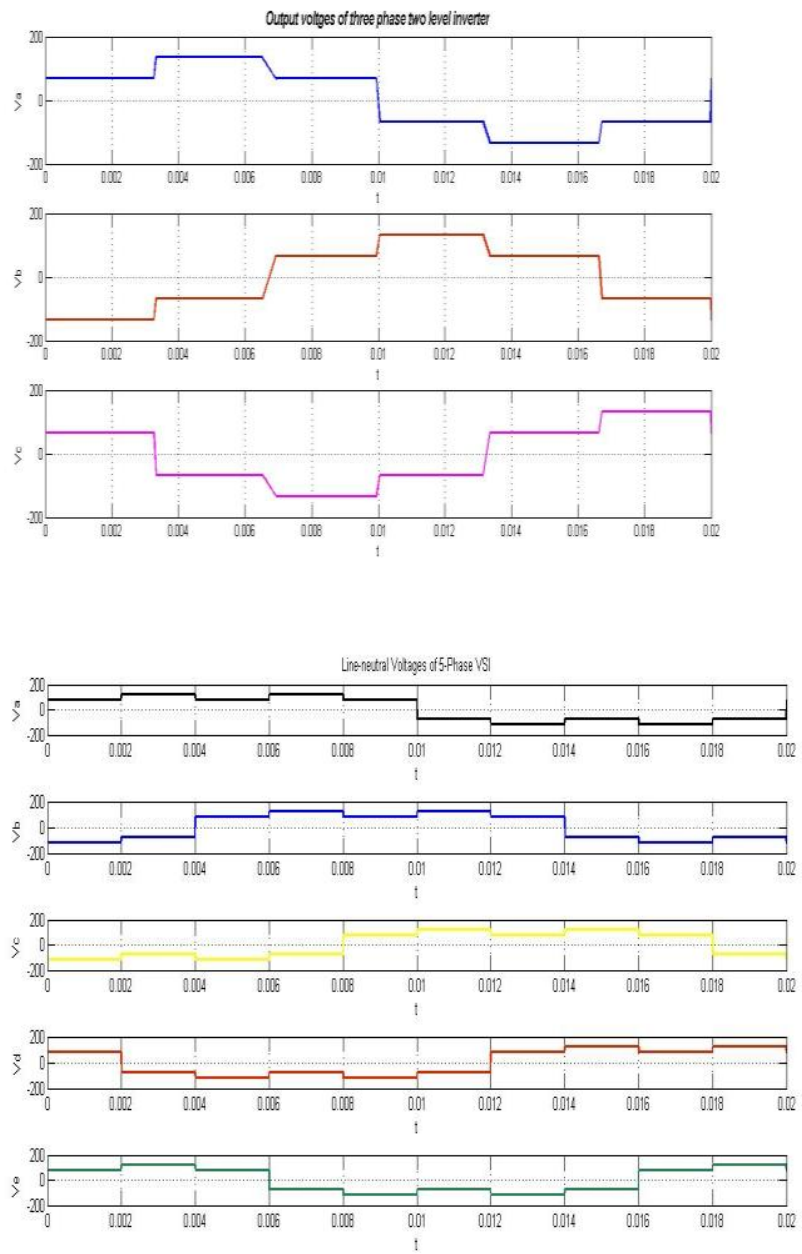

Fig.7 Matlab/simulation results for output phase voltages of Three phase two-level voltage source inverter and five phase two-level voltage source 

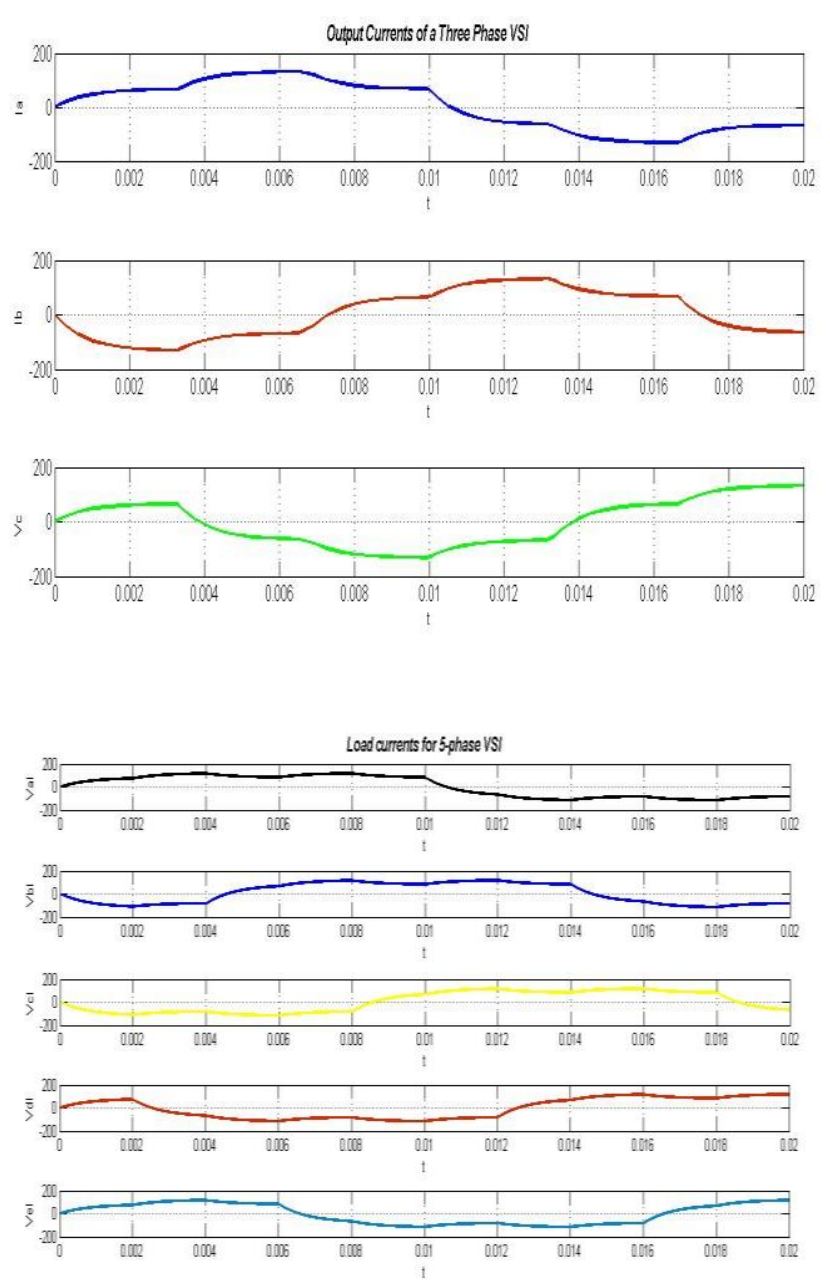

Fig.8 Matlab/simulation results for output load currents of Three phase two-level voltage source inverter and five phase two-level voltage source
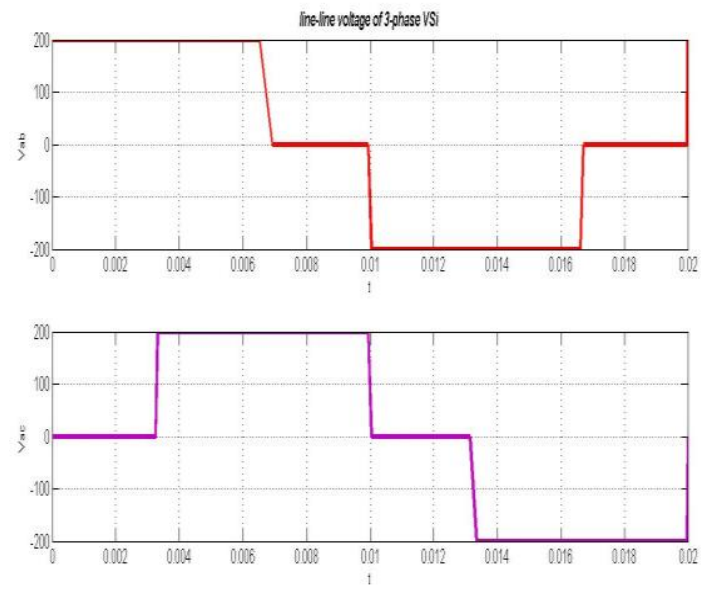
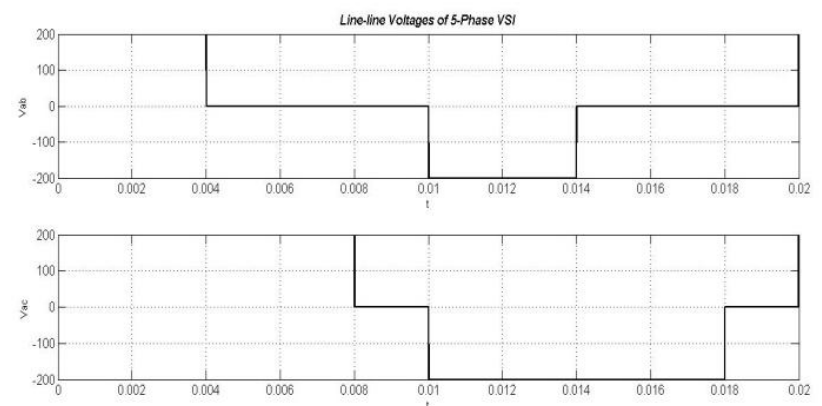

Fig.9 Matlab/simulation results for output line voltages of Three phase two-level voltage source inverter and five phase two-level voltage source
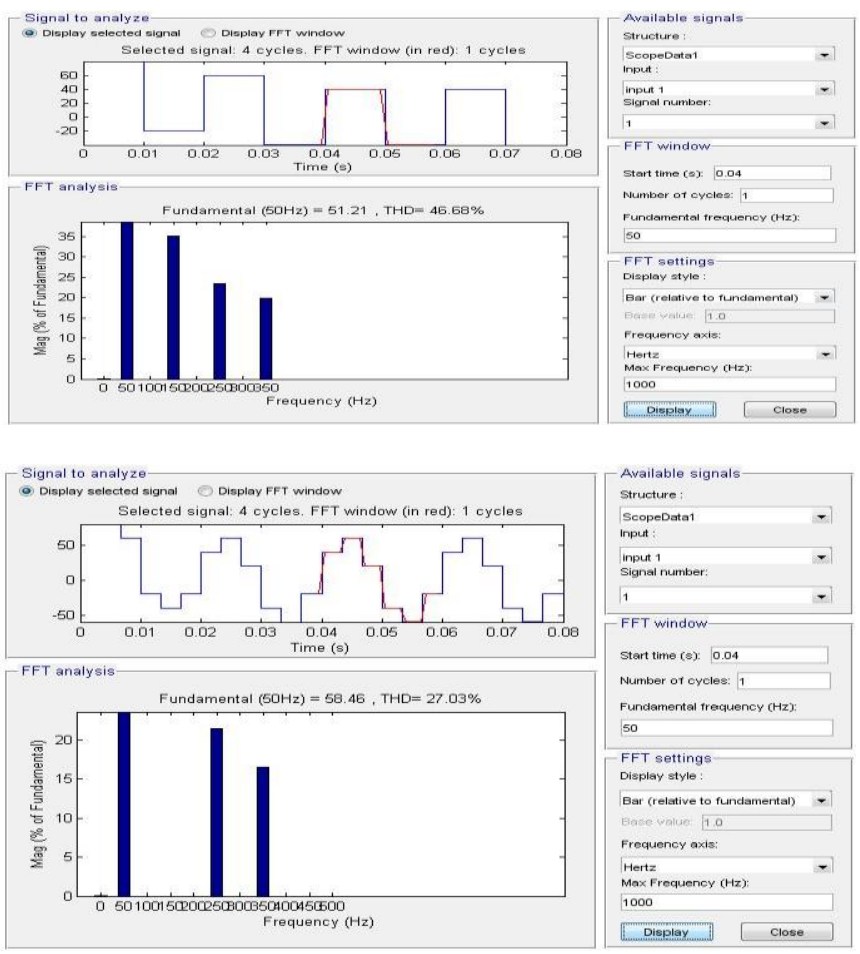

Fig.10 Matlab/simulation results for FFT analysis of five phase two level voltage source inverter with 1800 and 1200 conduction angles.

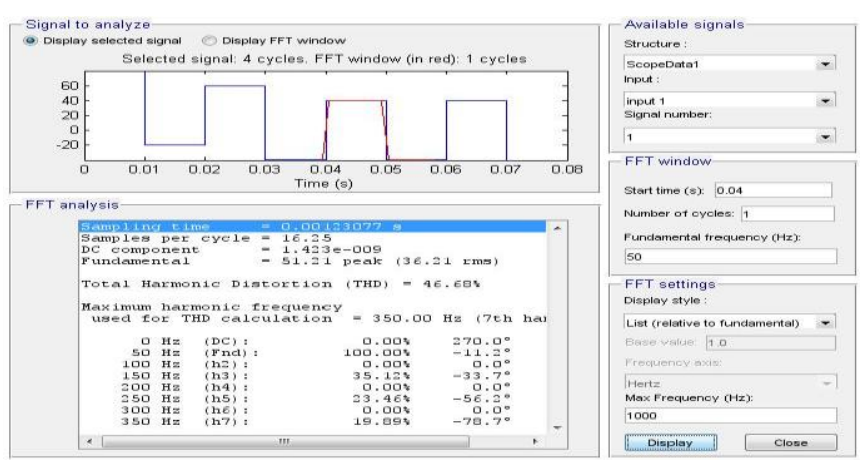




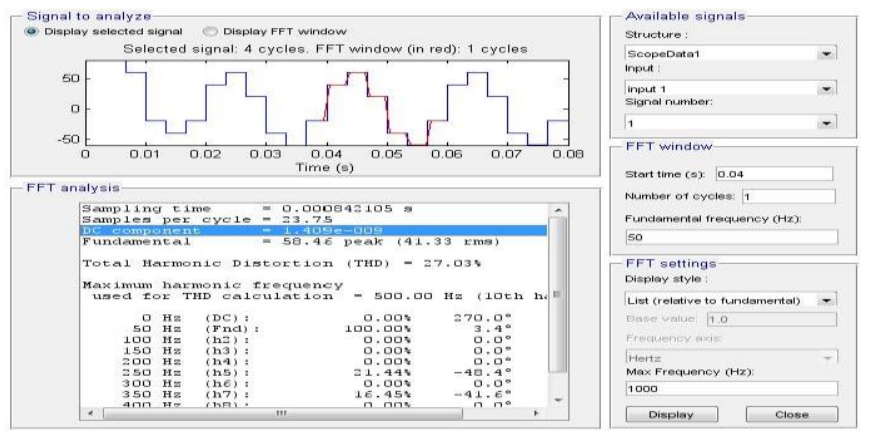

Fig.11 Matlab/simulation results for FFT analysis with different harmonic orders of five phase two level voltage source inverter with 1800 and 1200 conduction angles.

\section{CONCLUSIONS}

It has been advantages of like reduction in phase current, reliable in faulty conditions, reduction in current ripple as comparison between TPTLVSI and FPTLVSI. It can encourage of reduction of current rating of switches like IGBTS/MOSFET used in Voltage source inverters.

A comparison of total harmonic distortion in the output phase voltages of five-phase voltage source inverter for different conduction angle is presented. The conduction angles considered are $180^{\circ}, 162^{\circ}, 144^{\circ}, 126^{\circ}$, and $108^{\circ}$. Thus two more conduction states are included when compared to further prove the superiority of control at $120^{\circ}$ conduction mode. It is observed that the lowest THD is obtained for $120^{\circ}$ conduction mode.

This paper has reviewed analytical approach for five phase two level voltage inverter used in application of induction motor drive.

\section{REFERENCES}

[1] E. Levi, R. Bojoi, F. Profumo, H. A. Toliyat, and S. Williamson, "Multiphase induction motor drives-A technology status review," IET Electr. Power Appl., vol. 1, no. 4, pp. 489-516, 2007.

[2] Grandi, G. Serra, and A. Tani, "General analysis of multiphase systems based on space vector approach," in Proc. Int. Power Electr. Motion Control Conf. (EPE-PEMC), Portoroz, Slovenia, 2006, pp. 834-840.

[3] Y. Zhao and T. A. Lipo, "Space vector PWM control of dual three-phase induction machine using vector space decomposition," IEEE Trans. Ind.Appl., vol. 31, no. 5, pp. 1100-1109, Sep./Oct. 1995.

[4] P. S. N. de Silva, J. E. Fletcher, and B. W. Williams, "Development of space vectormodulation strategies for five-phase voltage source inverters," in Proc. Inst. Electr. Eng. Power Electr., Mach. Drives Conf. (PEMD), Edinburgh, U.K., 2004, pp. 650-655.

[5] D. Dujic, E. Levi,M. Jones, G. Grandi, G. Serra, and A. Tani, "Continuous PWM techniques for sinusoidal voltage generation with seven-phase voltage source inverters," in Proc. IEEE Power Electr. Spec. Conf. (PESC), Orlando, FL, 2007, pp. 47-52.

[6] G. Grandi, G. Serra, and A. Tani, "Space vector modulation of a seven phase voltage source inverter," in Proc. Int. Symp. Power Electron., Electr. Drives, Autom. Motion (SPEEDAM), Taormina, Italy, 2006, pp. 1149_ 1156.

[7] D. Dujic, M. Jones, and E. Levi, "Space-vector PWM for nine-phase VSI with sinusoidal output voltage generation," in Proc. IEEE Ind. Electron.Soc. Annu. Meeting (IECON), Taipei, Taiwan, 2007, pp. 1324- 1329.

\section{BIOGRAPHIES}

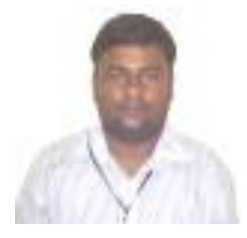

A. P. Desai has received the B.E degree in Electrical Engineering from South Veer Narmad South Gujarat University, Surat Gujarat, in 2008. Currently he studies in M.E. (electrical engineering) of Shantilal shah Engineering college,Bhavnagar Gujarat,india.

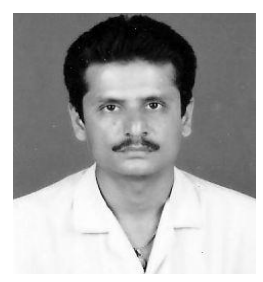

R. J. Motiyani has received the M.E degree in Electrical Power Engineering from M. S. University, Baroda, Gujarat in 2005. Currently he is working with S.N.Patel Institute of Technology \& Research Centre as Associate Professor in Electrical Engineering Department.

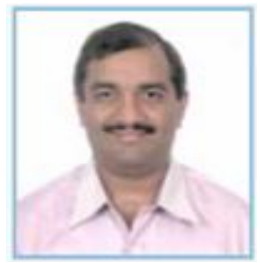

V.G.Bhuva is currently working with Shantilal Shah Engineering college, Bhavnagar, Gujarat, India as assistant Professor in Electrical Engineering Department.

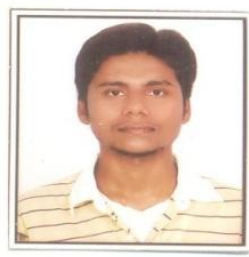

Jignesh.P.Desai has received the B.E degree in Electrical Engineering from South Veer Narmad South Gujarat University, Surat Gujarat, in 2009. Currently he studies in M.Tech. (Power System) of Nirma University. 